Check for updates

Cite this: Chem. Sci., 2019, 10, 8668

๑ All publication charges for this article have been paid for by the Royal Society of Chemistry

\section{Canonical DNA minor groove insertion of bisbenzamidine-Ru(II) complexes with chiral selectivity $\dagger$}

\author{
Mateo I. Sánchez, (D) a Gustavo Rama, (D) ${ }^{\mathrm{b}}$ Renata Calo-Lapido, ${ }^{a}$ Kübra Ucar, ${ }^{\mathrm{c}}$ \\ Per Lincoln, ${ }^{c}$ Miguel Vázquez López, (D) ${ }^{\mathrm{b}}$ Manuel Melle-Franco, ${ }^{\mathrm{d}}$ \\ José L. Mascareñas (iD *a and M. Eugenio Vázquez iD *a
}

\begin{abstract}
We report the first Ru(॥) coordination compounds that interact with DNA through a canonical minor groove insertion mode and with selectivity for $A / T$ rich sites. This was made possible by integrating a bisbenzamidine minor groove DNA-binding agent with a ruthenium(॥) complex. Importantly, one of the enantiomers $\left(\Delta-\left[R u(b p y)_{2} b 4 b p y\right]^{2+}, \Delta-4 R u\right)$ shows a considerably higher DNA affinity than the parent organic ligand and the other enantiomer, particularly for the AATT sequence, while the other enantiomer preferentially targets long AAATTT sites with overall lower affinity. Finally, we demonstrate that the photophysical properties of these new binders can be exploited for DNA cleavage using visible light.
\end{abstract}

Received 20th June 2019 Accepted 30th July 2019

DOI: $10.1039 / c 9 s c 03053 \mathrm{k}$

rsc.li/chemical-science
We reasoned that in the same way polyaromatic ligands, such as dppn, dppz or dpq, define the intercalative binding mode of traditional DNA-binding metal complexes, ${ }^{8}$ engineering an organic minor groove binder as a metal ligand could yield complexes capable of inserting into the minor groove of DNA, and thus display new DNA binding properties not observed with traditional metallointercalators. ${ }^{9,10}$ More specifically, we considered the use of aza-bisbenzamidines as model minor groove binders, owing to their synthetic accessibility and their well-established fluorogenic properties. ${ }^{11}$ This type of compound tends to insert into the minor groove of $\mathrm{A} / \mathrm{T}$ rich sequences with dissociation constants in the low $\mu \mathrm{M}$ range. ${ }^{12}$ Herein we describe the synthesis of several ruthenium(II) complexes incorporating bis-(methylamino-benzamidine)-2,2'bipyridine ligands, and demonstrate that they bind to A/T-rich DNA sequences by insertion of such a benzamidine ligand into the minor groove. Importantly, we also found that the DNA binding profile of these complexes is heavily dependent on their chirality, which not only affects their overall binding affinity, but also determines their preferred binding sequence.

\section{Results and discussion}

${ }^{a}$ Centro Singular de Investigación en Química Biolóxica e Materiais Moleculares (CiQUS), Departamento de Química Orgánica, Universidade de Santiago de Compostela, 15782 Santiago de Compostela, Spain.E-mail: eugenio.vazquez@usc.es ${ }^{b}$ Centro Singular de Investigación en Química Biolóxica e Materiais Moleculares (CiQUS), Departamento de Quimica Inorgánica, Universidade de Santiago de Compostela, 15782 Santiago de Compostela, Spain

'Department of Chemistry and Chemical Engineering, Chalmers University of Technology, SE 41296 Gothenburg, Sweden

${ }^{d}$ Ciceco - Aveiro Institute of Materials, University of Aveiro Campus Universitario de Santiago, Aveiro, 3810-193, Portugal

$\dagger$ Electronic supplementary information (ESI) available. See DOI: $10.1039 / \mathrm{c} 9 \mathrm{sc} 03053 \mathrm{k}$

\section{Synthesis and characterization of the bisbenzamidine complexes}

The aza-bisbenzamidine ligands and their corresponding complexes were synthesized as shown in Scheme $1 .^{11}$ Thus, reductive amination of 2,2'-bipyridine-4,4'-dicarbaldehyde (1a, Scheme 1), with commercially available 4 -aminobenzene carboximidamide dihydrochloride, afforded the desired bisbenzamidine-bipyridine ligand b4bpy in good yield. ${ }^{22}$ The reaction of this ligand with each of the enantiopure Hua and 
von Zelewsky's reagents, $\Lambda$ - and $\Delta$-cis-[Ru(bpy $\left.)_{2}(\mathrm{py})_{2}\right]^{2+},{ }^{13}$ afforded the enantiomeric complexes $\boldsymbol{\Lambda}-\mathbf{4 R u}\left(\Lambda-\left[\mathrm{Ru}(\mathrm{bpy})_{2} \mathbf{b} \mathbf{4} \mathbf{b p y}\right]^{2+}\right)$ and $\Delta-\mathbf{4 R u}\left(\Delta-\left[\mathrm{Ru}(\mathrm{bpy})_{2} \mathbf{b} \mathbf{b} \mathbf{b p y}\right]^{2+}\right)$, respectively. The same sequence of transformations starting with $2,2^{\prime}$-bipyridine-5, $5^{\prime}$ dicarbaldehyde (1) $\mathbf{b}$, Scheme 1) leads to the regioisomeric complexes $\quad \Lambda-5 R u \quad\left(\Lambda-\left[R u(b p y) ~_{2} \mathbf{b} 5 \mathbf{b p y}\right]^{2+}\right)$ and $\Delta-5 \mathbf{R u} \quad(\Delta-$ $\left[\mathrm{Ru}(\mathrm{bpy})_{2} \mathbf{b} 5 \mathbf{b} \mathbf{b y y}\right]^{2+}$ ), also in good yields (Scheme 1).

The CD spectra of both $\Lambda$-complexes $(\boldsymbol{\Lambda}-\mathbf{4 R u}$ and $\boldsymbol{\Lambda}-\mathbf{5 R u})$ are dominated by a large LC transition band with a positive Cotton effect at $285-310 \mathrm{~nm}$ and a broad and less intense metal-toligand charge transfer (MLCT) band centered at $c a .460 \mathrm{~nm}$, also displaying positive Cotton effects. These features are consistent with the $\Lambda$-configuration around the metal center in octahedral coordination compounds. ${ }^{14}$ Likewise, their enantiomeric complexes $(\boldsymbol{\Delta}-\mathbf{4 R \mathbf { R }}$ and $\boldsymbol{\Delta}-\mathbf{5 R \mathbf { R }})$ display mirror image CD spectra with negative Cotton effects (see the ESI $\dagger$ ).

\section{DNA binding of the bisbenzamidine-Ru(II) complexes}

Having the two pairs of enantiomeric complexes at hand, we studied their DNA binding properties by taking advantage of the intrinsic fluorogenic properties of the ruthenium(II) polypyridyl complexes..$^{15}$ Thus, successive aliquots of a $250 \mu \mathrm{M}$ solution of a short double stranded hairpin oligonucleotide containing an extended six-base-pair A/T-rich binding site (A3T3) were added to a $0.5 \mu \mathrm{M}$ solution of $\mathbf{\Lambda}-\mathbf{4 R u}$ in Tris-HCl buffer and the luminescence emission spectra upon irradiation at the benzamidine excitation wavelength $(329 \mathrm{~nm})$ were recorded after each addition. This resulted in a series of spectra displaying a progressive increase in the emission intensity of the $\mathbf{\Lambda}-\mathbf{4 R u}$ ${ }^{3}$ MLCT band at $605 \mathrm{~nm}$, which could be fitted to a one to one binding model including contribution from non-specific binding, with a dissociation constant of $K_{\mathrm{D}} \approx 0.62 \mu \mathrm{M}$

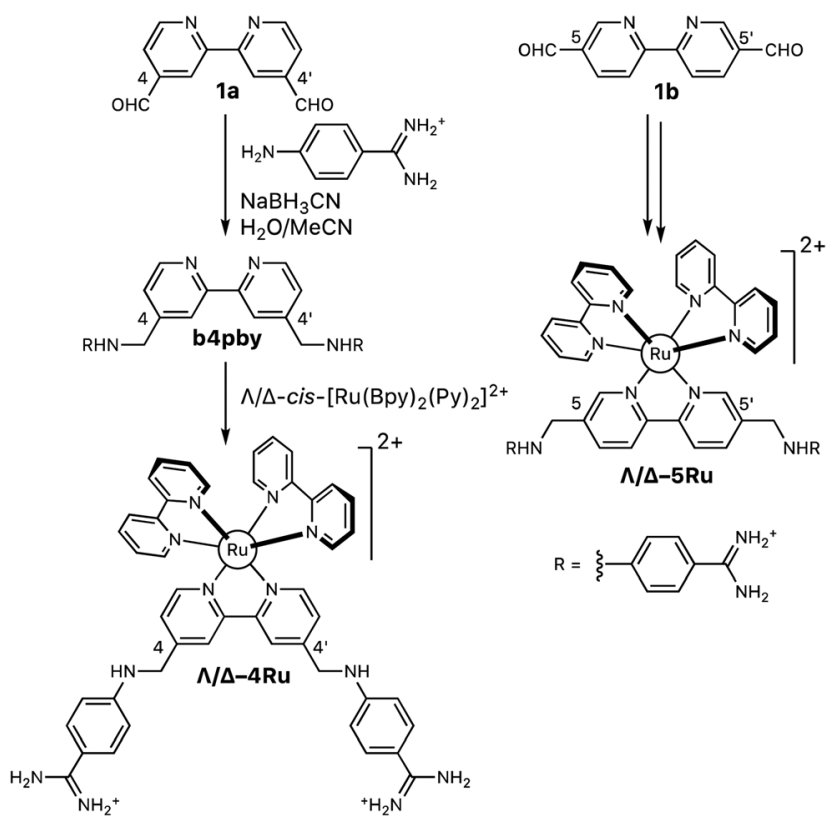

Scheme 1 Synthesis of the set of $\Lambda$ - and $\Delta$-bisbipyridyl ruthenium(॥) complexes containing the ligands b4bpy and b5bpy.
(Fig. 1a and Table 1, see the ESI $\dagger$ for details about curve fitting analysis). ${ }^{16}$ Titrations with other DNA oligonucleotides exhibiting five (A2T3) and four (A2T2) consecutive A/T base pairs resulted in progressively weaker binding. Not surprisingly, $\boldsymbol{\Lambda}$ 4Ru displayed considerably lower affinity for a G/C-rich oligo (G2C3). Similar experiments were carried out with the enantiomeric complex $\Delta-\mathbf{4 R u}$, the isomeric $\Lambda-5 R u$ and $\Delta-5 \mathbf{R u}$ complexes, and the parent bis-benzamidine ligands (b4bpy and b5bpy, $\lambda_{\text {exc }}=329 \mathrm{~nm} ; \lambda_{\mathrm{em}}=389 \mathrm{~nm}$ ). The resulting apparent dissociation constants are summarized in Table 1 and graphically compared in Fig. $1 \mathrm{~b}$.

The ligand b5bpy and its derivatives $\boldsymbol{\Lambda}-\mathbf{5 R u}$ and $\boldsymbol{\Delta}-\mathbf{5 R u}$ display lower affinity than its b4bpy counterparts. The reduced binding of b5bpy probably arises from its linear structure, which cannot simultaneously optimize the interactions of the two amidinium groups with the bottom of the DNA minor groove. ${ }^{12,17,18}$ Moreover,
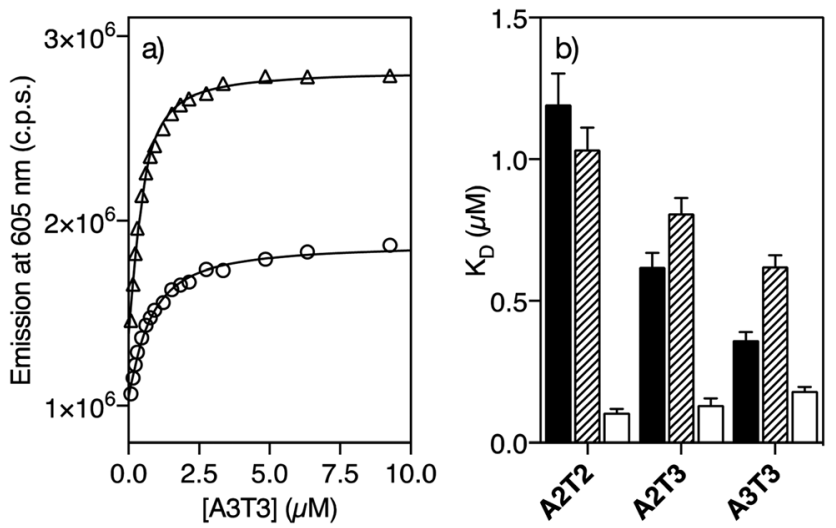

Fig. 1 (a) Representative titration profiles of $0.5 \mu \mathrm{M}$ solutions of $\boldsymbol{\Lambda}-4 \mathrm{Ru}$ $(O)$ and $\Delta-4 R u(\triangle)$ complexes with increasing concentration of the oligo A3T3. (b) Dissociation constants of b4bpy (black), $\Lambda$-4Ru (striped), and $\Delta-4 \mathrm{Ru}$ (white) with a set of $A / T$-rich oligonucleotides. Hairpin sequences (binding sites in italics): A3T3: 5'-GGC AAATT CAG $T_{5}$ CTG AAATT GCC-3'; A2T3: 5'-GGCG AATाT CGC T5 GCG AAATT CGCC-3'; A2T2: 5'-GGCG AATT CAGC T5 GCTG AATT CGCC-3'A/Trich binding sites, and the central hairpin loop $\left(T_{5}\right)$ is shown in italics. All titrations were performed in $20 \mathrm{mM}$ Tris- $\mathrm{HCl}$ buffer with $100 \mathrm{mM}$ $\mathrm{NaCl}, \mathrm{pH} 7.5$, at $298 \mathrm{~K}$

Table 1 Binding constants for the bipyridine-benzamidine ligands and their ruthenium(॥) coordination complexes ${ }^{a}$

\begin{tabular}{lllll}
\hline & A2T2 & A2T3 & A3T3 & G2C3 \\
\hline b4bpy & $1.19(0.11)$ & $0.62(0.05)$ & $0.36(0.03)$ & n.b. \\
$\mathbf{b 5 b p y}$ & $2.58(0.58)$ & $1.29(0.15)$ & $0.84(0.07)$ & n.b. \\
$\boldsymbol{\Delta}$-4Ru & $\mathbf{0 . 1 1 ( 0 . 0 1 )}$ & $0.13(0.02)$ & $0.18(0.01)$ & $1.69(0.09)$ \\
$\boldsymbol{\Lambda}$-4Ru & $\mathbf{1 . 0 4}(\mathbf{0 . 0 8})$ & $0.81(0.06)$ & $0.62(0.04)$ & $2.64(0.28)$ \\
$\boldsymbol{\Delta}$-5Ru & $4.24(0.49)$ & $3.64(0.26)$ & $3.08(0.16)$ & $4.90(0.05)$ \\
$\boldsymbol{\Lambda}$-5Ru & $4.04(0.76)$ & $3.81(0.76)$ & $3.24(0.28)$ & $3.63(0.39)$
\end{tabular}

${ }^{a} K_{\mathrm{D}}(\mu \mathrm{M})$ was measured in $20 \mathrm{mM}$ Tris- $\mathrm{HCl}$ buffer with $100 \mathrm{mM} \mathrm{NaCl}$, $\mathrm{pH} 7.5$, at $298 \mathrm{~K}$ and calculated from three independent titrations. The estimated $K_{\mathrm{D}}$ error is shown in brackets. n.b. indicates that no binding was observed under the experimental conditions used in the titrations. Hairpin oligonucleotide sequence of G2C3: $5^{\prime}$-GGCA GGCC CAGC $T_{5}$ GCTG GGCC TGCC-3'. 
$\Lambda-5 R u$ and $\Delta-5 R u$ showed weaker DNA binding than b5bpy, regardless of the chirality of the metal center. On the other hand, the ligand $\mathbf{b} \mathbf{4 b p y}$ and $\mathbf{\Lambda} \mathbf{- 4 R \mathbf { u }}$ display comparable binding affinities and a clear preference for those DNAs featuring longer $\mathrm{A} / \mathrm{T}$ sites, so titrations with oligos exhibiting six (A3T3), five (A2T3), and four (A2T2) consecutive $\mathrm{A} / \mathrm{T}$ base pairs resulted in progressively weaker dissociation constants (Table 1 and Fig. 1b). Remarkably, $\mathbf{\Delta - 4 R u}$ displays much higher affinity for all the above A/T-rich DNAs than b4bpy or $\Lambda$-4Ru, particularly for A2T2 $\left(K_{\mathrm{D}}=0.11 \mu \mathrm{M}\right.$, Table 1$)$. Indeed, its interaction with the A2T2 oligo is over 10 times stronger than that of its enantiomer $\boldsymbol{\Lambda} \mathbf{- 4 R u}$, or that of the parent organic ligand b4bpy. Hence, proper ligand engineering allowed transforming a weak and nonspecific DNA binder, such as $\left[\mathrm{Ru}(\mathrm{bpy})_{3}\right]^{2+19}$ into complexes capable of inserting into the minor groove of specific DNA sequences with high affinity. Curiously, in the case of the isomer b5bpy, the metal coordination has a negative effect on the affinity (e.g., $\Lambda / \Delta-\mathbf{5 R u} v s$. b5bpy).

\section{DNA binding occurs through insertion into the DNA minor groove}

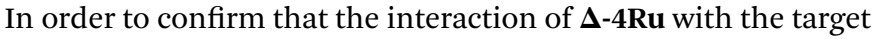
DNA occurs by insertion into the minor groove, we measured the circular dichroism spectra of the oligonucleotide A3T3 in the presence of increasing concentrations of the ligand b4bpy, $\boldsymbol{\Lambda}-\mathbf{4 R u}$, and $\Delta-\mathbf{4 R u}$. Incubation with b4bpy resulted in the appearance of a positive induced CD band at $c a .345 \mathrm{~nm}$, consistent with its insertion into the DNA minor groove (Fig. 2a). ${ }^{\mathbf{2 0 , 2 1}}$ Importantly, mixing the DNA with either $\mathbf{\Lambda - 4 R u}$ or $\Delta$-4Ru produced a similar induced CD band, although with reduced intensity compared to that of the free ligand $\mathbf{b 4 b p y}$, perhaps due to the conformational restrictions imposed by coordination to the metal ion (Fig. 2b). The observation of this induced CD band, which arises from a chiral twisting of the bisbenzamidine ligand, supports the formation of DNA complexes of similar nature to those formed with b4bpy. ${ }^{22}$

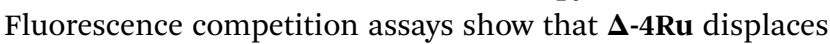
DAPI (4,6-diamidino-2-phenylindole) and Hoechst 33258, typical A/T-rich minor groove binders, very efficiently, ${ }^{23}$ thus reinforcing the hypothesis that these complexes insert into the DNA minor groove (Fig. 2c and S10 in the ESI $\dagger$ ). ${ }^{24}$ Linear Dichroism (LD) experiments, which provide information about the orientation of the bound complexes with respect to the DNA, ${ }^{25}$ were also consistent with minor groove insertion. Thus, the LD spectra of a reference intercalative complex $\Lambda$ $\left[\mathrm{Ru}(\mathrm{bpy})_{2} \text { phen }\right]^{2+}$ show a strong positive LD signal in the $\mathrm{B}(\mathrm{E})$ polarized MLCT band at $440 \mathrm{~nm}$, arising from the placement of the phen ligand almost coplanar to the DNA base pairs and the complex two-fold symmetry axis slightly rotated clockwise (by about $10^{\circ}$ ) from the ideal intercalation geometry. This arrangement results in a decreased LD at $440 \mathrm{~nm}$ for its enantiomer $\Delta$-[Ru(bpy $)_{2}$ phen $]^{2+}$ (Fig. 2d). ${ }^{26,29}$ By substituting the intercalative phen ligand with the minor groove binder $4 \mathbf{b p y}$, the $\mathbf{\Lambda} \mathbf{- 4 R u}$ enantiomer now shows a more negative LD band compared to $\boldsymbol{\Delta} \mathbf{- 4 R \mathbf { R }}$, which is unprecedented among mononuclear ruthenium polypyridyl complexes. This inversion in the relative intensities is consistent with the alignment of the
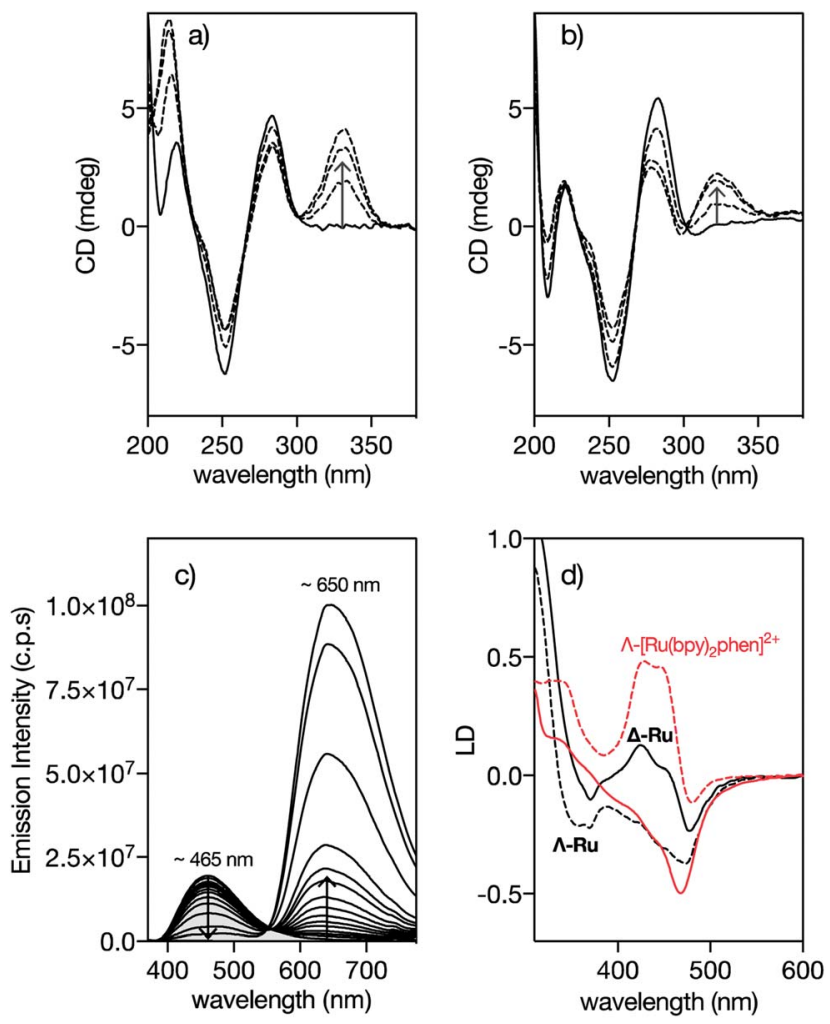

Fig. 2 Circular Dichroism spectra of $5 \mu \mathrm{M}$ solutions of the A3T3 oligo in $20 \mathrm{mM}$ Tris- $\mathrm{HCl}$ buffer with $100 \mathrm{mM} \mathrm{NaCl}, \mathrm{pH} 7.5$ (solid lines) in the presence of 1,3 and 5 eq. of (a) 4 bpy and (b) $\Lambda$-4Ru showing the induced $C D$ band at ca. $330 \mathrm{~nm}$ corresponding to the benzamidine chromophore. A3T3: 5'-GGC AAATTT CAG T5 CTG AAATIT GCC-3'; $A / T$-rich binding sites and the central hairpin loop $\left(T_{5}\right)$ are shown in italics. The CD spectra obtained upon incubation of the $\Delta-4 R u$ isomer with the A3T3 DNA are qualitatively the same as those for the enantiomeric $\boldsymbol{\Lambda}-4 \mathrm{Ru}$; (c) DAPI displacement assay showing a series of emission spectra of a mixture of $0.25 \mu \mathrm{M}$ DAPI and $0.5 \mu \mathrm{M} \mathrm{A2T2}$ in the presence of increasing concentration of $\Delta-4 R u$; (d) Linear dichroism (LD) spectra of flow-oriented calf thymus DNA with the two enantiomers of $4 \mathrm{Ru}$ (black lines, $\mathrm{P} / \mathrm{Ru}=20$ ) and $\left[\mathrm{Ru}(\mathrm{bpy})_{2} \text { phen }\right]^{2+}$ (red lines, $\mathrm{P} / \mathrm{Ru}=30$ ) in $10 \mathrm{mM} \mathrm{NaCl}{ }^{29} \Lambda$-enantiomers as dashed lines and $\Delta$ enantiomers as solid lines in both cases. Spectra are normalized to $A=$ 1 for the long wavelength absorption maximum of the free complex. The LD spectra are further normalized to perfect orientation $(S=1)$ by setting the $L D^{r}$ value at the DNA band at $260 \mathrm{~nm}$ to $-1.5 .^{29}$

substituted 4bpy ligand in the direction of the DNA minor groove, and a counter-clockwise rotation of the complex from the ideal intercalation geometry by about $45^{\circ}$, moving the $\mathrm{B}(\mathrm{E})$ transition away from the helix axis and consequently giving rise to a decreased, or even negative, LD at $440 \mathrm{~nm}$.

\section{Computational modeling of the interaction}

To gain some structural insight into the interaction of our molecules with the DNA, we performed modelling studies using previously tested docking procedures ${ }^{27}$ and taking as reference the high-resolution crystal structure of the Dickerson-Drew dodecamer, which features a short A/T-rich binding site in the middle of its sequence ( $5^{\prime}$-CGCGAATTCGCG-3', xA2T2). ${ }^{28}$ The lowest energy docking poses of the complexes $\Lambda-\mathbf{R u}$ and $\Delta-\mathbf{4 R u}$ 

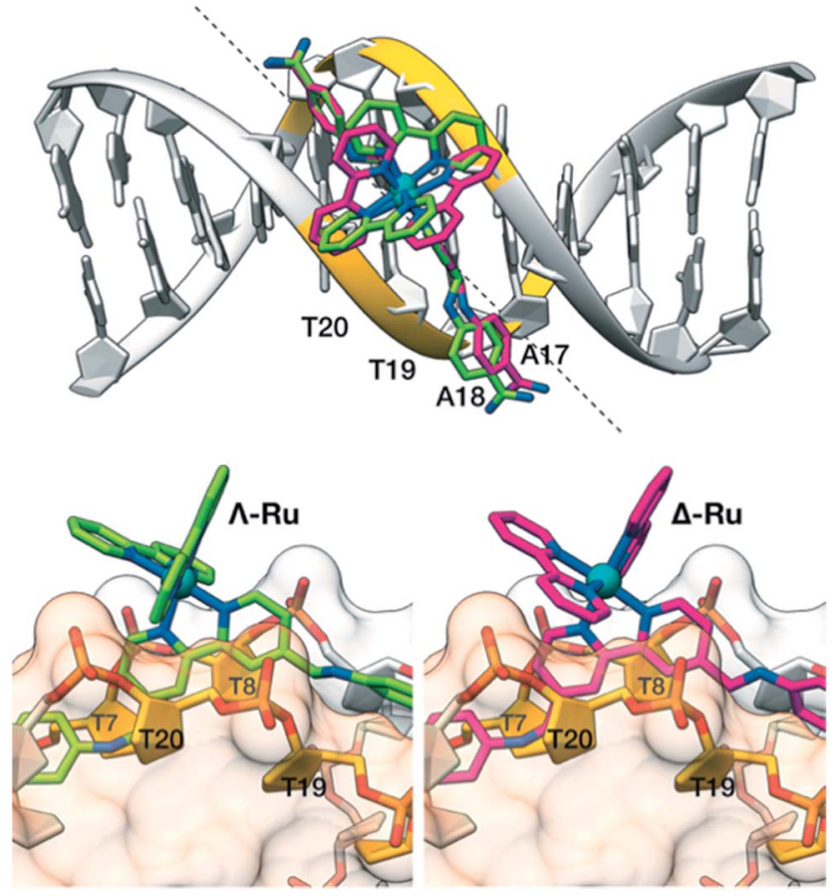

Fig. 3 Docking structures of $\boldsymbol{\Lambda}-\mathrm{Ru}$ (green) and $\boldsymbol{\Delta}-\mathbf{4 R u}$ (magenta). Top view: alignment of the b4bpy ligands with the minor groove in the Dickerson-Drew dodecamer (xA2T2). The dashed line forms a $45^{\circ}$ angle with the DNA axis and matches the approximate orientation of the b4bpy ligand in the complexes. Bottom left: side view of $\boldsymbol{\Lambda}-\mathrm{Ru}$ showing the bipyridine ligand between the phosphate groups flanking T20 (front, light orange surface) and T8 (back, light grey surface). Bottom right: the same view of $\boldsymbol{\Lambda}-\mathrm{Ru}^{33}$

on this DNA present the bisbenzamidine ligand inserted into the minor groove in the A/T-rich region of the oligonucleotide.

More importantly, the bulkier bipyridine ligands match the indentations between the T7-T8/T19-T20 phosphate groups in the DNA backbone (Fig. 3), allowing the benzamidine ligand to reach the bottom of the DNA minor groove. Docking studies with a different model DNA based on fiber diffraction data (fA2T2) ${ }^{30}$ resulted in most populated poses qualitatively similar to those observed with XA2T2. Importantly, the binding energies resulting from the docking experiments are highly dependent on the DNA model used in the calculations. Thus, the intermolecular binding energies obtained with the DNA fA2T2 were -16.5 and

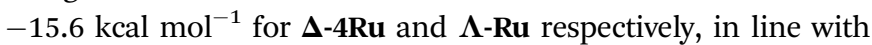
the observed experimental difference in the binding affinity. However, the interaction energy with $\mathbf{X A 2 T 2}$ turned out to be about $-20 \mathrm{kcal} \mathrm{mol}^{-1}$ for both isomers. Summing up, these docking studies support the minor groove binding mode for both $\Delta-\mathbf{4 R u}$ and $\boldsymbol{\Lambda}-\mathbf{R u}$ and also suggest that the strength and sequence selectivity are highly dependent on the microstructure of the DNA substrates, as previously reported for related minor groove binders. $^{31}$ The shape complementarity with the DNA minor groove plays a key role in the strength of the binding, as well as in the sequence discrimination between both enantiomeric forms, which ultimately appears to be related to the way in which the accessory bipyridine ligands match the DNA backbone. ${ }^{32}$ Taken together, these experimental and computational data demonstrate that through proper ligand engineering it is possible to obtain metal complexes that selectively recognize DNA through a canonical minor groove insertion mechanism.

\section{Study of the bisbenzamidine-Ir(III) analogs $\Delta$-4Ir and $\Lambda$-4Ir}

We also studied the DNA binding of the 2-phenylpyridine cyclometalated iridium(III) complexes containing the minor groove binding ligand b4bpy. These monocationic complexes have roughly the same geometry as dicationic ruthenium(II) complexes, but lower charge $(+1)$. Thus we synthesized the complexes $\Delta$ - and $\Lambda$-[Ir(ppy $\left.)_{2} \mathbf{b} \mathbf{4 b p y}\right]^{+}(\Delta-4$ Ir and $\Lambda$-4Ir respectively; ppy $=2$-phenylpyridine), by reaction of $\mathbf{b 4 b p y}$ with a dimeric bis(2-phenylpyridinato) iridium chloride precursor $\left[(\text { ppy })_{2} \operatorname{Ir}(\mu-\mathrm{Cl})\right]_{2}$, followed by HPLC resolution of the resulting enantiomeric mixture (see the ESI $\dagger$ ). ${ }^{34}$

The interaction of these complexes with DNA was studied by steady-state luminescence titrations monitoring the emission from the complexes at $575 \mathrm{~nm}$ upon irradiation of the benzamidine fluorophore at $329 \mathrm{~nm}$ (ESI $\dagger$ ). As shown in Table 2, both $\Delta$-4Ir and $\Lambda$-4Ir display similar trends to $\Delta-\mathbf{4 R u}$ and $\Lambda-4 R u$, although with slightly reduced affinities, which might be likely related to the lower charge of these complexes. Thus, for example, $\boldsymbol{\Delta}$-4Ir also displays higher affinity for A2T2 than $\boldsymbol{\Lambda}$-4Ir. Interestingly, the two iridium isomers show different sequence selectivity, so while the affinity of $\boldsymbol{\Delta}$-4Ir for DNA is higher for shorter A/T-tracts, $\boldsymbol{\Lambda}$-4Ir shows a marked preference for longer

Table 2 Binding constants for the bipyridine-benzamidine iridium(III) complexes $^{a}$

\begin{tabular}{lllll}
\hline & A2T2 & A2T3 & A3T3 & G2C3 \\
\hline $\mathbf{b 4 b p y}$ & $1.19(0.11)$ & $0.62(0.05)$ & $0.36(0.03)$ & n.b. \\
$\Delta$-4Ir & $0.27(0.09)$ & $0.49(0.03)$ & $1.01(0.12)$ & $1.44(0.09)$ \\
$\mathbf{\Lambda}$-4Ir & $1.15(0.13)$ & $0.62(0.04)$ & $0.47(0.03)$ & $0.70(0.05)$
\end{tabular}

${ }^{a} K_{\mathrm{D}}(\mu \mathrm{M})$ was measured in $20 \mathrm{mM}$ Tris- $\mathrm{HCl}$ buffer with $100 \mathrm{mM} \mathrm{NaCl}$, $\mathrm{pH} 7.5$, at $298 \mathrm{~K}$ and calculated from three independent titrations. The estimated $K_{\mathrm{D}}$ error is shown in brackets. n.b. if no significant binding is observed.

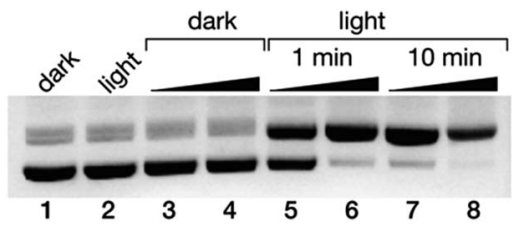

Fig. 4 Ethidium bromide-stained agarose gels $(0.7 \%)$ of the photocleavage of $25 \mathrm{ng} \mu \mathrm{L}^{-1}$ pCDNA3.1(+) in $20 \mathrm{mM}$ Tris- $\mathrm{HCl}$ buffer with $100 \mathrm{mM} \mathrm{NaCl}, \mathrm{pH} 7.5$, with $\Delta-4 \mathrm{Ru}$. All lanes contain the plasmid pCDNA3.1(+); lane 1: plasmid in the absence of $\Delta-4 R u$ in the dark; lane 2 , the same plasmid after 10 min of irradiation in the absence of the $\Delta$ 4Ru complex; lanes 3 and 4: 20 and $100 \mu \mathrm{M} \Delta$-4Ru in the dark; lanes 5 and 6: 20 and $100 \mu \mathrm{M} \Delta$-4Ru irradiated for 1 min; lanes 7 and 8: 20 and $100 \mu \mathrm{M} \Delta-4 \mathrm{Ru}$ irradiated for $10 \mathrm{~min}$. Irradiation was performed with a Thorlabs M455L3 Royal Blue (455 nm) Mounted High-Power LED, $1000 \mathrm{~mA}$, using a custom made setup (see the ESI†). 
A/T-rich sites. Curiously, the affinity for G/C-rich oligos is higher than for the ruthenium analogs.

\section{Photo-endonuclease activity of $\Delta-4 R u$}

Finally, we studied the potential application of these newly developed DNA minor groove binders as photo-endonucleases. It is known that irradiation of trisbipyridyl $\mathrm{Ru}(\mathrm{II})$ complexes gives rise to a ${ }^{3}$ MLCT (metal-to-ligand charge transfer) excited state that can act as a photosensitizer to generate singlet oxygen $\left({ }^{1} \mathrm{O}_{2}\right),{ }^{35}$ which ultimately leads to DNA strand breaks. ${ }^{36}$ Thus, a $50 \mathrm{ng} \mu \mathrm{L}^{-1}$ solution of the pCDNA3.1 $(+)$ plasmid was incubated with increasing concentration of the complex $\Delta-\mathbf{4 R u}(20$ and $100 \mu \mathrm{M})$ and irradiated with a $455 \mathrm{~nm}$ LED source for either 5 or $10 \mathrm{~min}$, and the resulting mixtures were analyzed by agarose electropho-

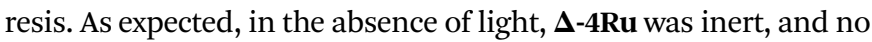
new bands indicating the degradation of the pCDNA3.1 $(+)$ plasmid were observed. However, the irradiated solutions displayed new bands in the agarose gel consistent with the illumination time and a concentration-dependent scission of the plasmid (Fig. 4). It is important to note that the parent ruthenium complex $\left[\mathrm{Ru}(\mathrm{bpy})_{3}\right]^{2+}$ does not induce the light-promoted DNA cleavage, as it is not capable of interacting with DNA.

\section{Conclusions}

In summary, ruthenium(II) coordination complexes containing a designed bis-benzamidine ligand selectively bind to A/T-rich sequences in DNA by means of a classic minor groove insertion mechanism. To our knowledge, this type of interaction has not been demonstrated for metal-based DNA-binding agents. Importantly, the two enantiomers display markedly different DNA binding properties, so $\boldsymbol{\Delta} \mathbf{- 4 R u}$ binds more strongly than $\mathbf{\Lambda} \mathbf{- 4 R u}$ to all the studied DNA sites and preferentially to those with a short A/ T site (AATT) with $\sim 10$-fold higher affinity than $\mathbf{\Lambda}-\mathbf{4 R u}$. In contrast the $\mathbf{\Lambda - 4 R u}$ isomer preferentially binds to DNA with longer $\mathrm{A} / \mathrm{T}$ sites (A3T3) and shows only residual binding affinity for the shorter DNA A2T2 preferred by its enantiomer. Finally, $\mathbf{\Delta - 4 R u}$ exhibited efficient nuclease activity upon irradiation, which might find applications in photodynamic therapy.

\section{Conflicts of interest}

There are no conflicts to declare.

\section{Acknowledgements}

Financial support from the Spanish grants CTQ2015-70698-R, SAF2016-76689-R and Orfeo-cinqa network CTQ2016-81797REDC; the Ministerio de Ciencia, Innovación y Universidades of Spain, RTI2018-099877-B-I00; the Xunta de Galicia (2015-CP082, ED431C 2017/19, Centro singular de investigación de Galicia accreditation 2016-2019, ED431G/09), the European Union (European Regional Development Fund - ERDF), and the European Research Council (Advanced Grant No. 340055) are gratefully acknowledged. We also acknowledge the support from the Portuguese Foundation for Science and Technology, FCT, (IF/
00894/2015) and CICECO - Aveiro Institute of Materials, FCT Ref. UID/CTM/50011/2019, financed by national funds through the FCT/MCTES. M. E. V. also acknowledges the support of the Fundación Asociación Española Contra el Cáncer (AECC) (IDEAS197VAZQ grant). We also thank A. Arda and J. Jiménez-Barbero (CIC bioGUNE) for carrying out the preliminary spectroscopic characterization.

\section{References}

1 (a) K. L. Haas and K. J. Franz, Chem. Rev., 2009, 109, 49214960; (b) P. C. A. Bruijnincx and P. J. Sadler, Curr. Opin. Chem. Biol., 2008, 12, 197-206; (c) M. A. Jakupec, M. Galanski, V. B. Arion, C. G. Hartinger and B. K. Keppler, Dalton Trans., 2008, 183-194; (d) J. K. Barton, Science, 1986, 233, 727-734.

2 (a) B. M. Zeglis, V. C. Pierre and J. K. Barton, Chem. Commun., 2007, 4565-4579; (b) M. R. Gill, J. Garcia-Lara, S. J. Foster, C. Smythe, G. Battaglia and J. A. Thomas, Nat. Chem., 2009, 1, 662-667; (c) M. R. Gill and J. A. Thomas, Chem. Soc. Rev., 2012, 41, 3179-3192; (d) J. Rodríguez, J. Mosquera, J. R. Couceiro, M. E. Vázquez and J. L. Mascareñas, Angew. Chem., Int. Ed., 2016, 55, 15615-15618; (e) B. C. Poulsen, S. Estalayo-Adrián, S. Blasco, S. A. Bright, J. M. Kelly, D. Clive Williams and T. Gunnlaugsson, Dalton Trans., 2016, 45, 18208-18220.

3 (a) C. L. Kielkopf, K. E. Erkkila, B. P. Hudson, J. K. Barton and D. C. Rees, Nat. Struct. Biol., 2000, 7, 117-121; (b) H. Song, J. T. Kaiser and J. K. Barton, Nat. Chem., 2012, 4, 615-620.

4 (a) A. E. Friedman, J. C. Chambron, J. P. Sauvage, N. J. Turro and J. K. Barton, J. Am. Chem. Soc., 1990, 112, 4960-4962; (b) H.-K. Liu and P. J. Sadler, Acc. Chem. Res., 2011, 44, 349-359. 5 (a) P. Guo, A. A. Farahat, A. Paul, N. K. Harika, D. W. Boykin and W. D. Wilson, J. Am. Chem. Soc., 2018, 140, 14761-14769; (b) S. Neidle, Nat. Prod. Rep., 2001, 18, 291-309; (c) M. E. Vazquez, A. M. Caamaño, J. Martínez-Costas, L. Castedo and J. L. Mascareñas, Angew. Chem., Int. Ed., 2001, 40, 4723-4725; (d) O. Vázquez, M. E. Vázquez, J. B. Blanco, L. Castedo and J. L. Mascareñas, Angew. Chem., Int. Ed., 2007, 46, 6886-6890.

6 (a) J. K. Barton, J. M. Goldberg, C. V. Kumar and N. J. Turro, J. Am. Chem. Soc., 1986, 108, 2081-2088; (b) C. V. Kumar, J. K. Barton and N. J. Turro, J. Am. Chem. Soc., 1985, 107, 5518-5523; (c) A. Papakyriakou, G. Malandrinos and A. Garoufis, J. Inorg. Biochem., 2006, 100, 1842-1848; (d) H. Ahmad, A. Wragg, W. Cullen, C. Wombwell, A. J. H. M. Meijer and J. A. Thomas, Chem.-Eur. J., 2014, 20, 3089-3096; (e) I. Gamba, I. Salvadó, G. Rama, M. Bertazzon, M. I. Sánchez, V. M. Sánchez-Pedregal, J. Martínez-Costas, R. F. Brissos, P. Gamez, J. L. Mascareñas, M. Vázquez López and M. E. Vázquez, Chem.-Eur. J., 2013, 19, 13369-13375.

7 (a) A. Greguric, I. D. Greguric, T. W. Hambley, J. R. AldrichWright and J. G. Collins, J. Chem. Soc., Dalton Trans., 2002, 849-855; (b) H. Niyazi, J. P. Hall, K. O'Sullivan, G. Winter, T. Sorensen, J. M. Kelly and C. J. Cardin, Nat. Chem., 2012, 4, 621-628; (c) J. P. Hall, P. M. Keane, H. Beer, K. Buchner, 
G. Winter, T. L. Sorensen, D. J. Cardin, J. A. Brazier and C. J. Cardin, Nucleic Acids Res., 2016, 44, 9472-9482; (d) H. Song, J. T. Kaiser and J. K. Barton, Nat. Chem., 2012, 4, 615-620; (e) A. N. Boynton, L. Marcélis and J. K. Barton, J. Am. Chem. Soc., 2016, 138, 5020-5023.

8 A. C. Komor and J. K. Barton, Chem. Commun., 2013, 49, 3617-3630.

9 S. Neidle, Nat. Prod. Rep., 2001, 18, 291-309.

10 (a) C. Kaes, A. Katz and M. W. Hosseini, Chem. Rev., 2000, 100, 3553-3590; (b) T. Wang, N. Zabarska, Y. Wu, M. Lamla, S. Fischer, K. Monczak, D. Y. W. Ng, S. Rau and T. Weil, Chem. Commun., 2015, 51, 12552-12555; (c) E. Wachter, D. K. Heidary, B. S. Howerton, S. Parkin and E. C. Glazer, Chem. Commun., 2012, 48, 9649-9651.

11 (a) O. Vázquez, M. I. Sánchez, J. Martínez-Costas, M. E. Vázquez and J. L. Mascareñas, Org. Lett., 2010, 12, 216-219; (b) O. Vázquez, M. I. Sánchez, J. L. Mascareñas and M. E. Vázquez, Chem. Commun., 2010, 46, 5518-5520; (c) M. I. Sánchez, O. Vázquez, J. Martínez-Costas, M. Eugenio Vázquez and J. L. Mascareñas, Chem. Sci., 2012, 3, 2383-2387; (d) R. Nanjunda and W. D. Wilson, Curr. Protoc. Nucleic Acid Chem., 2012, https:// currentprotocols.onlinelibrary.wiley.com/doi/abs/10.1002/ 0471142700.nc0808s51; (e) E. Pazos, J. Mosquera, M. E. Vázquez and J. L. Mascareñas, ChemBioChem, 2011, 12, 1958-1973.

12 (a) A. Paul, A. Kumar, R. Nanjunda, A. A. Farahat, D. W. Boykin and W. D. Wilson, Org. Biomol. Chem., 2017, 15, 827-835; (b) P. Guo, A. A. Farahat, A. Paul, N. K. Harika, D. W. Boykin and W. D. Wilson, J. Am. Chem. Soc., 2018, 140, 14761-14769.

13 (a) X. Hua and A. Von Zelewsky, Inorg. Chem., 1991, 30, 37963798; (b) X. Hua and A. von Zelewsky, Inorg. Chem., 1995, 34, 5791-5797; (c) M. Brissard, O. Convert, M. Gruselle, C. Guyard-Duhayon and R. Thouvenot, Inorg. Chem., 2003, 42, 1378-1385.

14 (a) C. Fu, M. Wenzel, E. Treutlein, K. Harms and E. Meggers, Inorg. Chem., 2012, 51, 10004-10011; (b) S. G. Telfer, T. M. McLean and M. R. Waterland, Dalton Trans., 2011, 40, 3097-3108.

15 (a) C. V. Kumar, J. K. Barton and N. J. Turro, J. Am. Chem. Soc., 1985, 107, 5518-5523; (b) M. R. Gill, H. Derrat, C. G. W. Smythe, G. Battaglia and J. A. Thomas, ChemBioChem, 2011, 12, 877-880; (c) M.-J. Han, L.-H. Gao, Y.-Y. Lü and K.-Z. Wang, J. Phys. Chem. B, 2006, 110, 23642371; (d) S. Arounaguiri and B. G. Maiya, Inorg. Chem., 1999, 38, 842-843; (e) C. Hiort, P. Lincoln and B. Norden, J. Am. Chem. Soc., 1993, 115, 3448-3454.

16 P. Thordarson, Chem. Soc. Rev., 2010, 40, 1305-1323.

17 (a) D. Roeland Boer, A. Canals and M. Coll, Dalton Trans., 2008, 399-414; (b) C. Bailly and J. B. Chaires, Bioconjugate Chem., 1998, 9, 513-538; (c) B. S. Reddy, S. M. Sondhi and J. W. Lown, Pharmacol. Ther., 1999, 84, 1-111; M. A. Ismail, R. K. Arafa, R. Brun, T. Wenzler, Y. Miao, W. D. Wilson, C. Generaux, A. Bridges, J. E. Hal and D. W. Boykin, J. Med. Chem., 2006, 49, 5324-5332.
18 Although it has been reported that water-mediated contacts can compensate for poor shape complementarity, the length of the bipyridine ligand (more than $20 \AA$ between the aminidium carbon atoms) would likely not allow the mechanism to operate. (a) B. Nguyen, S. Neidle and W. D. Wilson, Acc. Chem. Res., 2009, 42, 11-21; (b) B. Nguyen, M. P. H. Lee, D. Hamelberg, A. Joubert, C. Bailly, R. Brun, S. Neidle and W. D. Wilson, J. Am. Chem. Soc., 2002, 124, 13680-13681.

19 A. B. Tossi and J. M. Kelly, Photochem. Photobiol., 1989, 49, 545-556.

20 N. Holmgaard List, J. Knoops, J. Rubio-Magnieto, J. Idé, D. Beljonne, P. Norman, M. Surin and M. Linares, J. Am. Chem. Soc., 2017, 139, 14947-14953.

21 The changes in the CD spectra are different to those observed with intercalative complexes: S. D. Choi, M. S. Kim, S. K. Kim, P. Lincoln, E. Tuite and B. Nordén, Biochemistry, 1997, 36, 214-223.

22 Circular dichroism experiments require high concentrations (5-10 times the $K_{\mathrm{D}} \mathrm{s}$ ), which is why no differences are observed between $\boldsymbol{\Delta} \mathbf{- 4 R \mathbf { R }}$ and $\mathbf{\Lambda} \mathbf{- 4 R \mathbf { R }}$ using this technique.

23 T. A. Larsen, D. S. Goodsell, D. Cascio, K. Grzeskowiak and R. E. Dickerson, J. Biomol. Struct. Dyn., 1989, 7, 477-491.

24 Earlier studies have shown that DAPI is particularly suited for the study of DNA-binding complexes through competitive titrations: C. B. Spillane, J. A. Smith, J. L. Morgan and F. R. Keene, J. Biol. Inorg Chem., 2007, 12, 819-824.

25 A. Rodger, G. Dorrington and D. L. Ang, Analyst, 2016, 141, 6490-6498.

26 P. Lincoln, A. Broo and B. Nordén, J. Am. Chem. Soc., 1996, 118, 2644-2653.

27 D. Bouzada, I. Salvadó, G. Barka, G. Rama, J. MartínezCostas, R. Lorca, Á. Somoza, M. Melle-Franco, M. E. Vázquez and M. Vázquez López, Chem. Commun., 2018, 54, 658-661.

28 L. Lercher, M. A. McDonough, A. H. El-Sagheer, A. Thalhammer, S. Kriaucionis, T. Brown and C. J. Schofield, Chem. Commun., 2014, 50, 1794-1796 (PDB ID: 4C64).

29 Data for $\left[\mathrm{Ru}(\mathrm{bpy})_{2} \text { phen }\right]^{2+}$ from: P. Lincoln and B. Nordén, $J$. Phys. Chem. B, 1998, 102, 9583-9594.

30 Model built with 3 dna software: A. V. Colasanti, X.-J. Lu and W. K. Olson, J. Visualized Exp., 2013, e4401.

31 (a) B. J. Pages, D. L. Ang, E. P. Wright and J. R. AldrichWright, Dalton Trans., 2015, 44, 3505-3526; (b) C. Oguey, N. Foloppe and B. Hartmann, PLoS One, 2010, 5, e15931; (c) S. Laughlin-Toth, E. K. Carter, I. Ivanov and W. D. Wilson, Nucleic Acids Res., 2017, 45, 1297-1306; (d) P. M. Keane, F. E. Poynton, J. P. Hall, I. V. Sazanovich, M. Towrie, T. Gunnlaugsson, S. J. Quinn, C. J. Cardin and J. M. Kelly, Angew. Chem., Int. Ed., 2015, 54, 8364-8368; (e) P. M. Keane, J. P. Hall, F. E. Poynton, B. C. Poulsen, S. P. Gurung, I. P. Clark, I. V. Sazanovich, M. Towrie, T. Gunnlaugsson, S. J. Quinn, C. J. Cardin and J. M. Kelly, Chemistry, 2017, 23, 10344-10351; $(f)$ J. P. Hall, F. E. Poynton, P. M. Keane, S. P. Gurung, J. A. Brazier, D. J. Cardin, G. Winter, T. Gunnlaugsson, I. V. Sazanovich, 
M. Towrie, C. J. Cardin, J. M. Kelly and S. J. Quinn, Nat. Chem., 2015, 7, 961-967.

32 C. Laughton and B. Luisi, J. Mol. Biol., 1999, 288, 953-963. 33 Molecular graphics obtained with UCSF Chimera, by the Resource for Biocomputing, Visualization, and Informatics at the University of California, San Francisco, with support from NIH P41-GM103311. E. F. Pettersen, T. D. Goddard,
C. C. Huang, G. S. Couch, D. M. Greenblatt, E. C. Meng and T. E. Ferrin, J. Comput. Chem., 2004, 25, 1605-1612.

34 S. Sprouse, K. A. King, P. J. Spellane and R. J. Watts, J. Am. Chem. Soc., 1984, 106, 6647-6653.

35 J. N. Demas, E. W. Harris and R. P. McBride, J. Am. Chem. Soc., 1977, 99, 3547-3551.

36 M. B. Fleisher, K. C. Waterman, N. J. Turro and J. K. Barton, Inorg. Chem., 1986, 25, 3549-3551. 